\title{
The Reality of Participation in Decision-making: A Field Study on the Supervisory Offices in Riyadh City
}

\author{
Mohammad Y. Kentab \\ Ph.D. in Educational Administration, Advisor at the Deputyship for Planning \& Information, Ministry of Education, \\ Kingdom of Saudi Arabia \\ *Corresponding Author: mkentab@moe.gov.sa
}

Copyright $\bigcirc 2018$ by authors, all rights reserved. Authors agree that this article remains permanently open access under the terms of the Creative Commons Attribution License 4.0 International License

\begin{abstract}
The study problem is about the reality of participation in decision-making. The problem of the study was identified through the following question: What is the reality of participation of the subordinates in the supervisory offices in Riyadh city in decision-making? The study aimed to identify the levels of participation in decision-making among subordinates in the supervisory offices in Riyadh city, identify the obstacles that prevent participation in decision-making, and learn the sample's suggestions for developing participation in decision-making. A descriptive approach was used for this study. The study population is represented by the supervisory office employees in Riyadh city. The researcher selected a regulated random sample of 150 of the total study population. The data was collected through a questionnaire that included several themes according to the questions and objectives of the study. The questionnaire was subjected to standards of honesty and consistency. The study reached several results, as follows: 1 . The level of participation in decision-making is high in the individual decision-making manager, who informs the subordinates to implement the decision and presents the problem to subordinates so that they contribute to finding alternatives; then, he chooses the alternative that he deems appropriate to solve the problem. The manager listens to the views and suggestions of the subordinates before making a final decision. 2. The key obstacles to participation in decision-making are the lack of efficient leadership that limits the participation of subordinates in decision-making, as well as the limited delegation of decision-making power to subordinates, and the non-delegation of powers to subordinates. 3. The most important suggestions of the samples to develop participation in decision-making include the interest in holding training courses for subordinates so that their participation in the decision-making is fruitful, and that the subordinates have a good knowledge of the methods of participation appropriate to the work tasks, and training courses to be held to the seniors on the delegation of powers. In the light of the findings, a set of recommendations has been
\end{abstract}

developed that can contribute to the development of participation in decision-making.

Keywords Decision-making Participation, Decision, Supervisory Offices, Decision-making Obstacles, Public Education, Leadership

\section{Introduction}

The decision-making process is one of the most important and influential elements in the life of organizations. It is the essence of the administrative leadership. It is the starting point for all the jobs and tasks within it. The success of the manager depends to a large extent on the success of the decisions he makes.

The process of decision making is an important and fundamental process of management. It is the driver for human resource efforts and activities. Therefore, the decision-making process must be understood. Subordinates need to be able to choose the best decision-making method, and this can be honed through training programs and courses to improve decision-making skills and address the lack of experience and efficiency (Al-Ghamdi, 2015 p. 69) [4].

The decision-making process is also one of the most important functions of the manager in any organization. Administrative decision-making is not limited to a specific administrative function. It is rooted in planning, organization, coordination, direction, and control. Therefore, administrative decision-makers face increasing challenges that are difficult to control, including: globalization, intense competition, communication and informational revolution, and the complexity and volume of organizations. The importance of participation in decision-making is highlighted by the position that management occupies in our contemporary life. It has been linked to the daily work of the human being, his family life, and in any area of human activity, because 
decision-making is one of the basic tasks of the administration and its main focus in administrative work. Thus, the decision-making process became the focus of admin process and the beating heart of management (Al-Khamis, 2011, p. 2) [8].

The participation of subordinates in the management of decision-making in organizations gives the staff a degree of autonomy in carrying out their work, by allowing him to express their opinions regarding their jobs and their relation to other jobs in the organization. On the other hand, participation in administrative decision-making is a successful management step to increase motivation to influence the behavior of individuals for the better.

The researcher believes that the issue of administrative reform in the Kingdom of Saudi Arabia is still a major goal that the state strives to achieve through the continuous administrative reform of all central and local government organizations and educational institutions. Participation in decision-making is an important tool that contributes to organizational change. Due to the importance of this issue in achieving administrative development and reform, the attention of the researcher was focused on the reality of subordinates' participation in decision-making.

\subsection{Problem of the Study}

Decision-making is the basic process around which the functions of the administration revolve and decision-making that is based on the participation of individuals will contribute to the success of this decision (Mustafawi, 2017, p. 82) [19].

Participation in decision-making is one of the preventive incentives for performance according to the theories of motivation and stimulation in organizational behavior. Giving subordinates an opportunity to participate in the decision-making processes of the organizations they work in will help them achieve satisfaction, psychological self-respect, and self-realization, which are the highest levels of individuals' needs.

Some of the studies conducted in this field have emphasized the importance of involving subordinates in bringing about organizational change, as the groups that did not participate in the change have shown great resistance to change, and the complaints of subordinates have increased. In this sense, the problem of the study was formulated through the following question: What is the reality of participation in decision making of the supervisory offices' employees in Riyadh?

\subsection{Importance of the Study}

This study draws its importance from the issue it handles, which is participation in decision-making. In theoretical terms, this study will help identify the trend towards work of subordinates in supervisory offices through the levels of participation in decision-making, as well as the theoretical coverage of the subject literature to determine the levels of participation in such educational organizations, thus filling the shortage of local and Arab literature on measuring the participation of subordinates.

On the other hand, this study aims to develop recommendations that may be useful in the adoption of programs that correspond to the needs of subordinates in educational supervisory offices and support their participation. Finally, it is hoped that this study will help to adopt new mechanisms for development.

\subsection{Objectives of the Study}

- Identify the levels of participation in decision-making of subordinates in the supervisory offices in Riyadh City.

- Identify the obstacles that hinder the participation of subordinates in the supervisory offices in Riyadh City.

- Identify the suggestions of subordinates in the supervisory offices in Riyadh City to develop participation in decision-making.

\subsection{Study Questions}

- What are the levels of participation in decision-making of subordinates in the supervisory offices in Riyadh City?

- What are the obstacles that hinder the participation of subordinates in the supervisory offices in Riyadh City?

- What are the suggestions of subordinates in the supervisory offices in Riyadh City to develop participation in decision-making?

\subsection{Terminology of Study}

\subsubsection{Administrative Decision}

The administrative decision is known as the observation of the problem and its definition, identification, and analysis, setting a standard or a test to collect information, and the introduction of several solutions, the choice of solution, and employment of the same (Al-Hassoun, 2017, p. 321) [6].

\subsubsection{Decision Making Process}

The decision-making process is that process which involves selecting an alternative from several alternatives to achieve specific goals (Al-Ghamdi, 2015, p. 75) [4].

Decision-making in this study is defined as the best choice among the alternatives available in dealing with a specific situation or handling a particular problem related to work.

\subsubsection{Participation in Decision-making}

Participating in decision-making in the field of 
administrative application is defined as the manager's call to his subordinates and meeting with them to discuss and analyze their administrative problems and try to reach the best possible solutions for them. Being involved in setting solutions suitable for administrative problems enhances their trust (Al-Khamis, 2011, p. 25) [8].

Participation in decision-making is defined as an "invitation by the leader to his subordinates and meeting with them to discuss their administrative problems and to analyze them and try to reach the best possible solutions to them, which creates their confidence, to involve in developing appropriate solutions to administrative problems" (Mohammed, 2013, p. 47) [18].

Participation in decision-making is also seen as a kind of thinking where choices are plans or paths of action, and evidence is an imagined outcome. Decision-making may be the most important type of thinking, as it involves selecting other mental performance strategies (Abu Allam, 2014, p. 540) [2].

Participation in decision-making also means that individuals are mentally engaged in the work that helps to contribute to the objectives of the group and the participation of those responsible for them, thus helping to realize the expected results of participation (Zeitouni, 2015, p. 173) [24].

It refers to the leader's involvement of his subordinates in the decision-making, implementation, and evaluation (Shalaby, 2015, p. 15) [21].

It is also the "ability of the individual to identify the problem facing him and to identify the causes and factors affecting it, the choice between alternative solutions, and the choice of the best alternatives available to him in light of both the potential available to him and his personal view, implementation of this solution, and follow up on the consequences (Sobh, 2015, p 850) [23].

The above definitions show that participation in decision-making is (Al-Qahtani, 2016, p. 150) [9]:

- A mental process

- An organized process

- Based on information and knowledge structure

- Seeks to solve a problem and develop a vision or mechanism of action

- Depends on the choice among possible alternatives

Through the above, the researcher explains that participation in decision-making is the contribution of subordinates in making administrative decisions in various forms and degrees of contribution to decision-making.

\section{Study Literature}

\subsection{Theoretical Framework}

\subsubsection{The Importance of Participation in Decision-making}

Being guided by the opinions of others at various levels of management is necessary in the decision-making process. It is known that there is no expert in everything that everyone needs the help, assistance, and opinion of others, whether they are seniors, colleagues, or subordinates. The individual person, regardless of the level of his education or maturity, cannot be aware of all aspects of the problems he faces, both at the individual level and at the organizational level. In order to find solutions to these problems, it is necessary to involve others. Therefore, participation is one of the most important foundations of administration.

The decision-making process is influenced by the level of participation by subordinates. Abdul Rasoul (2010, p. 124) [1] believes that participation is seen as a kind of influence and supervision imposed by the subordinates on the decision-making process, noting that a part of the results of these decisions will be borne by those subordinates. The trend towards participation in decision-making appeared when attention was first paid to the humanitarian component in the early 1930s, when the tendency to involve several people in decision-making began to emerge from the realization that a group is more committed to the implementation of a decision when they are involved in the decision-making. Participation is a mental state through which the individual contributes to achieving the organization's targets. Effective leadership in the organization gives attention to participation and gives the opportunity to participants to interact freely, express opinions, and consult about the decision to inform the subordinates of their importance and their identity, which, therefore, gives them a sense of responsibility for implementing the decision.

Sobh (2015) [23] pointed out that the importance of participation in decision-making comes from the fact that it leads to the individual's knowledge of his responsibilities before his decision and gives him responsibility for the decision that affects people or the result of decision-making. In view of the rapid and successive changes in society, citizens need to make decisions in order to face the problems, which may be either of a personal nature or collective. If they do not have the skills to participate in decision-making, there will be difficulties in making good decisions and solving the social and personal problems they face.

Therefore, collective decisions are healthier and more accurate than individual decisions. Groups perform better than individuals. While the group spends more time solving problems, its final decision is more precise and useful and less mistakes occur for various reasons, including that the group's knowledge is better and more precise than the individual's knowledge, and the group has more choices and alternatives in decision-making processes than the individual.

As mentioned above, participation in decision-making process is one of the salient features of any administrative 
process in an organization and, therefore, has many benefits. It leads to the freedom to express the views of the target audience, allows them to contribute to proposals, creates a good and appropriate climate to encourage and accept change, leads to the development of administrative leaders in the lower grades, and helps facilitate and improve communication between managers and subordinates. For individuals who have the opportunity to participate, their energies and potential creativity towards achieving the objectives of the organization raise, which helps to improve the quality of the decision taken.

\subsubsection{Levels of Participation in Decision Making}

There is a variation in the grades and levels of participation that the manager or leader allows his subordinates to take. These grades are influenced by the administrative style he follows in the decision-making process. It is known that the administrative patterns range from the authoritarian pattern, in which the manager insists on focusing power in his hand, to the democratic pattern, in which the manager or the leader allows his subordinates to be responsible for making decisions. There are several administrative patterns between these two patterns. Accordingly, the grades and levels of participation differ according to the prevailing administrative pattern (Shehab, 1995 , p. 205) [22]. The levels of participation vary as follows:

- Decision is made and then informed to the subordinates: where the manager or the leader makes the decision alone and then informs the subordinates and the reporting process does not include explanation of the reasons for the decision or persuade subordinates or try to urge them to accept, but imposes on the subordinates to implement the decision taken.

- Decision is made and then justified: At this level, the manager takes the decision and not only informs the subordinates, but explains the justification of the decision and its advantages and attempts to persuade them to accept, and the purpose of this is to mitigate the impact of his individual decision or fear of the possibility of resistance by subordinates to the decision and non-cooperation in its implementation.

- The manager makes the decision and then calls for a dialogue about it: At this level, the manager, after decision making, invites the subordinates, allows dialogue with them on the decision, and identifies their views on the decision and its implications, with the aim of responding to their questions and removing their fears and making sure that they understand and be convinced of the decision (Al-Amri, 2011, p. 21) [3].

- The manager makes a preliminary decision, leaving room open for change: At this level, the manager makes a preliminary decision and then presents it to his subordinates. He then gives them the opportunity to express their opinions, suggestions, and views on the initial decision, which may prompt the manager to amend the decision or choose other alternatives. The manager shall have the power to determine the final decision, to amend or not to amend the decision.

- The manager presents the problem and invites the subordinates to submit proposals and solutions: At this level, the manager presents the subject problem of the decision and asks them to diagnose the problem, determine the reasons, and submit proposals and solutions. The manager may offer subordinates the opportunity to offer proposals and solutions. Then, the manager chooses between alternatives and proposals made by subordinates.

- The manager identifies the problem, the constraints on its solution, and requests the subordinates to make the decision. Here, the manager identifies the problem and the limits that the decision must be within, and then cooperates with the group, as any other member, to reach the appropriate decision so that the solution is what is agreed upon by everyone (Al-Rahmano, 2016, p. 30) [10].

- Delegating the matter to subordinates to diagnose the problem and reach a decision: At this level, the manager delegates the whole matter to the subordinates, starting from the identification of the problem and diagnosis to identifying alternatives and then reaching the final decision. This delegation includes all stages of decision-making, and the decision reached by the subordinates is final. The manager here may set the framework or the boundaries that the decision should be within. The manager may or may not participate in the deliberation and discussion meetings of the subordinates. In the case of participation in these meetings, his role is limited to coordinating and reconciling different trends and views rather than imposing his opinion or influence on subordinates (Shehab, 1995, p. 205) [22].

The levels of participation in decision-making vary according to the level of decision-making, but this variance has no clear effect on the way they are made, their components, or their degree of influence. Al-Harahsha (2014) [5] points out that participation in decision-making falls into three levels:

\subsubsection{Descending Decisions}

This type of decision is issued by the highest levels in the organization and these decisions are important and dangerous, as they relate to the whole organization; 
therefore, they apply to un-programmed decisions or non-routine decisions. They are also concerned with the study of ambiguous or complex issues that are decided on only by senior officials, who are trusted to make decisions in the best interests of the organization and are assigned to set goals and policies at higher organizational levels.

\subsubsection{Ascending Decisions}

This type of decision is not a decision in the strict technical sense. These decisions are no more than opinions or observations expressed by the lower or executive levels to the senior officials to make the final decision thereon. These observations and views reflect certain issues at the level of junior officials, or the inability to make the appropriate decision because of the lack of precedents or procedures to be guided with in this regard or because of conflicting matters.

\subsubsection{Routine or Personal Initiative Decisions}

These decisions fall under the powers given to executives and their assistants. This kind of routine decision is dominated by the nature of implementation and the choice of the appropriate method to achieve the goals set or resulting from the personal initiative.

It is clear from the above that the degree of participation varies according to the administrative behavior of the manager and the approach he is taking to involve his subordinates in solving the problems that they face in following his decisions.

\subsubsection{Conditions for Participation in Decision Making}

There is a set of different conditions for participation in decision-making in order to be effective and achieve the objectives of the decision taken. The most important of these conditions is that the subordinate must be able to engage psychologically in the participation activities, be free from obstacles that prevent him from reorganizing the pattern of his own objective in the light of the new experience, have a minimum limit of intelligence to enable him to capture the meanings and contents of the issues under consideration, be realistic, and have the desire to participate. This means that the person who believes that the knowledge of the manager is better and that the decision-making process is not his business may not have a strong motive if he has the opportunity to participate.

On the other hand, the subordinate must see the link between his own lifestyle and the issues under consideration. When he realizes that participation may affect his future in a way that increases the positive elements and reduces the negative elements in his life, he will be stimulated. The subordinate should be able to express his desires and feel that he is making some kind of contribution.

It is clear from the above that the success of participation depends on identifying the categories of subordinates that are allowed to participate at different levels in the organization. Participation should include all those affected by the decision and those who are concerned, who need to be consulted, and opportunity for discussion must be given to subordinates by holding meetings and interviews that allow them to make decisions.

\subsubsection{Hindrances to Participation in Decision Making}

The participation process in decision-making faces many different hindrances that can be clarified as follows:

\subsubsection{Fear of Decision Making}

Rizk (2013) [20] pointed out that managers tend to avoid making decisions that entail many changes and whose results are not known.

\subsubsection{Lack of Data and Information}

One of the most important difficulties in the process of participation in decision-making is the lack of data and information on the problem that is required to be decided. Abdul Rasoul (2010) [1] believes that this is due to the lack of efficiency of those who collect, arrange, and evaluate information; the weakness of the information system on which they rely, in terms of technical and technological levels; the limited time available to collect data and information; the lack of flow of data and information due to weak automated communication; and the decision-maker's personality.

Thus, it is clear that human behavior plays an important role in the decision-making process. It is recognized that the decision-making process can be influenced by the personal behavior of the decision-maker himself, who is either affected by external influences, such as social and economic conditions, or by internal influences, such as psychological stress, trends, beliefs, values, ideas, experiences, as well as the inability of the decision-maker to identify and evaluate available alternatives and choose the appropriate one.

\subsubsection{Inappropriate Decision Time}

Administrative pressures sometimes impose insufficient time on the decision-maker so that he does not have the opportunity to study and discuss the problem. These factors include the lack of time available for subordinates to participate in decision-making, in addition to the lack of participation by subordinates in decision-making and the lack of skills required to achieve the required level of effectiveness; the lack of an effective communication system; the fear of responsibility; the hesitation of some decision-makers in the process of making it; their reluctance to initiate the process and boldly confront problems and difficult conditions; and the inefficiency of the decision-maker in terms of qualification and specialization in the administrative field. (Abdul Rasoul, 2010, pp. 121-122) [1].

Thus, it is clear that managers' postponement of a decision to the last moment leads to an inaccurate analysis 
of the problem, as well as a decrease in the number of alternatives available due to the lack of time.

\subsubsection{Failure to Distinguish between the Problem and its Symptoms}

Al-Swaidi (2014) [12] believes that symptoms are a reflection of the problem, and, sometimes, the decision-maker focuses on the symptoms and tries to find solutions to them. Therefore, decision-making on handling symptoms will not solve the problem that caused these symptoms.

Rizk (2013) [20] added two other elements: the failure to determine the circumstances of the decision and the creation of conclusions using unreliable source. For the first element, the circumstances surrounding the decision must be identified, which affect the effectiveness of the solution provided by the decision to the problem under consideration, and there is more than one criterion for judging a decision that leads to a conflict among the alternatives available for decision-making. The second element is the creation of conclusions using unreliable sources, where the information obtained by the decision-maker is the input to the decision-making process; the information and opinions must therefore be distinguished; the decision-maker often deals with the views he hears as facts and takes the decision based on these views, which ultimately leads to low-quality decisions.

\subsubsection{Suggestions for Developing Participation in Decision-making}

There are many different suggestions that help with decision-making. Al-Hourani (2013) [7] believes in the importance of managers encouraging subordinates to participate in decision-making processes by providing them with incentives. Managers should also be aware of the type of decision they make and that there are types preferred by managers. These patterns may not be effective in all situations or environments. It is, therefore, advisable for managers to find ways to take advantage of the benefits offered by other styles and to provide training courses for managers in the decision-making process and patterns to improve the quality and effectiveness of decisions.

Al-Khamis (2011) [8] believes in the importance of increasing incentives for subordinates to encourage them to participate in decision-making, and to encourage leaders to adopt a decentralized leadership approach that allows subordinates to participate in decision-making and to enhance the confidence of leaders in the abilities of their subordinates, as well as encourage them to participate in decision-making. It is also necessary to clarify the objectives of work to subordinates sufficiently to enhance their participation in decision-making, as well as to strengthen channels of communication between leaders and their subordinates, thereby increasing the participation of subordinates in the decision-making process and directing leaders not to favor some of their subordinates in the participation in decision-making.

The researcher adds to the above a number of other suggestions that help in the development of participation in decision-making as follows:

- Increase the pace of delegation by the manager to his subordinates in the adoption of administrative decisions after he identified the problem by giving them the powers required to implement the work because of the increase of confidence in subordinates.

- Increase the subordinates' desire to participate in decision-making by giving them confidence in trying to involve them in the problems that may face managers in their work and ask them to give solutions and ideas that they may see as appropriate to solve these problems.

- Reduce the workload of subordinates and the use of modern scientific methods that help in participation in decision-making and training them and creating coordination between departments.

- Encourage research in the field of participation in decision-making to fill gaps in this field in order to develop knowledge.

\subsection{Study Literature}

Al-Sufiani's study, (2012) [11] "The Degree of Teachers' Participation in School Decision Making, A Field Study from the Point of View of Secondary School Teachers in Taif Governorate," aimed at identifying the degree of participation of teachers in making school decisions related to student affairs, teachers, curricula, methods of implementation, local community, school facilities, and local affairs. The study community consisted of all teachers of public secondary schools in Taif Governorate amounting 1031 teachers, of which 380 were selected in a random sampling method, and the questionnaire was used as a tool for study. The study reached a range of different results as follows:

- The degree of teachers' participation in making school decisions (in the five fields) in total was low at an average of (3.44).

- The degree of participation of teachers in making school decisions related to student affairs was generally medium, except for one statement with low degree of participation, which measured the approval on the program of scientific visits to students.

- There were statistically significant differences at the level of significance $(0.05)$ among the averages of the individuals' assessment of the study sample for the grades of participation in decision making in the field of student affairs due to the variable years of experience in favor of teachers whose experience exceeds 15 years. 
Al-Hourani's study states that (2013) [7] "A comparison between the method of decision-making among male and female managers, a case study on UNRWA's education program." This study aimed at identifying the difference between male and female managers in the decision-making process and their patterns in the Gaza Strip, and identifying the relationship between demographic variables and the decision-making process. The study community consisted of all male and female managers in the Department of Education in the Gaza Strip amounting (243) male and female managers. The study was applied to a random sample of (151) male and female managers. The questionnaire was used as a tool for study. The descriptive analytical method was used for study. The study reached a number of different conclusions that can be clarified as follows:

- There are no statistically significant differences on the level of knowledge, nor the level of information availability due to gender in the decision making process. There are statistically significant differences in the level of participation in decision making due to the gender in favor of females. There are no differences on the pattern of decision making due to gender.

- There are statistically significant differences in the fields of (intuitive, avoiding and spontaneous) due to age in favor of those aged (51) years and above. There are statistically significant differences for the field of spontaneous attributed to the academic qualification in favor of those having master and $\mathrm{PhD}$ degrees.

- There are no statistically significant differences in decision-making patterns due to the years of experience. The predominant pattern in decision making among male and female managers is the logical and then dependent pattern. There is a positive relationship between the level of being "dependent, logical," the level of knowledge and reading, and the level of participation and information availability in the decision-making of the respondents, while a relationship between intuition, spontaneity, and avoidance is absent.

Larry's study, (2013) [17] "Teachers' awareness of their role in decision-making in some of the Wayne State selected intermediate schools." The study aimed at identifying the extent of teachers' participation in decision-making. The study used the descriptive analytical method. The questionnaire was used as a tool for study. The sample included 326 male and female teachers in 100 intermediate schools in Detroit State. The study concluded with various results including:

- Teachers wish to participate in decision-making at the basic structural level.

- Participation in decision-making provides teachers with some form of supervision in their working life.
- High-efficiency teachers in intermediate schools have a strong desire to participate and make decisions in the planning, organization and curriculum development processes.

- Teachers need experience and training to increase their desired effectiveness in making decisions.

Larry's (2013) [17] study, "Teachers' awareness of their role in decision-making in some of the Wayne State selected intermediate schools," aimed to identify the extent of teachers' participation in decision-making. The study used a descriptive analytical method. The questionnaire was used as a tool for study. The sample included 326 male and female teachers in 100 intermediate schools in Detroit State. The study concluded with various results, including:

- Teachers wish to participate in decision-making at the basic structural level.

- Participation in decision-making provides teachers with some form of supervision in their work life.

- High-efficiency teachers in intermediate schools have a strong desire to participate and make decisions in the planning, organization, and curriculum development processes.

- Teachers need experience and training to increase their desired effectiveness in making decisions.

Mohammed's (2013) [18] study, "The reality of participation in decision-making among faculty members in Algerian universities, a field study," aimed to identify the level of participation in decision-making among faculty members in Algerian universities and to learn whether there are statistically significant differences attributed to the participation of the faculty members in decision-making. The main study community consisted of 320 members of staff, of which (130) are from the University of Algiers, (69) from the University of Oran, and (121) from the University of Constantine out of the original community of (1476) members. To achieve the objectives of the study, the questionnaire was used as a tool for collecting information. The study concluded that the level of participation in decision-making among faculty members in Algerian universities is generally low at $80 \%$. There are also no statistically significant differences among the three Algerian universities (Oran, Algeria, and Constantine) attributed to the variable of participation in decision-making among faculty members.

Castler's study (2014) [13], "Analyzing the relationship between teachers' participation in decision-making, organizational climate, and management style in their schools in Minnesota." The study aimed at analyzing the relationship between teachers' participation in decision-making, the organizational climate, and the management style in their schools in Minnesota. The study sample consisted of (13) schools characterized by its central administration, and (13) schools whose administration was characterized by decentralization. In order to achieve the objectives of the study, the researcher described the real participation of teachers in 
decision-making in their schools through the relationship between the organizational climate of schools and their management style. He analyzed the relationship between teacher participation and management style. The study had the following results:

- The participation of teachers in schools whose administration was characterized by decentralization was better than that of teachers in schools whose administration was characterized by centralization.

- Schools that have been characterized by decentralization had an open climate rather than schools whose administration has been centralized.

Dalton's study, (2014) [15] "The awareness of principals and teachers of intermediate schools to the degree of participation in decision-making in Texas," aimed at identifying and comparing the perceptions of intermediate school principals and teachers on the degree of participation in decision-making in Texas. The study sample consisted of two groups of principals and teachers. The researcher developed a tool that included five dimensions: planning, curriculum, budget, employment, and teacher development. These dimensions were the focus of participation in decision-making. The study reached a number of different results as follows:

- Managers understand that teachers are more involved in the five dimensions than teachers themselves perceive their participation, that is, there are differences between the perceptions of principals and teachers in the degree of participation.

- Managers recognize that teachers are more involved in budgeting and employment than in other areas (planning, curriculum, and teacher development) and more than the teachers' perception, i.e. there are differences between principals and teachers' perceptions of teachers' participation.

- Principals and teachers agreed on the importance of teacher participation in decision-making in the dimensions of curriculum and teacher development.

- There were differences in perception between principals and teachers in the degree of participation of teachers in budget, employment, and planning.

Al-Ghamdi's (2015) [4] study, "The reality of administrative decision-making process of managers of public education schools in Madinah," aimed at understanding the reality of the decision-making process among the managers of general education schools in Madinah and identifying obstacles that may limit its effectiveness, as well as exploring the methods of the managers of public education schools in Medina that may improve it. In order to achieve the objectives of the study, a survey descriptive approach was used. The questionnaire was used by Al-Hadhoud (1996) and was applied to all principals in primary, middle and secondary schools for boys in Al-Madinah. The study concluded that the general arithmetic average of the views of the study community on the reality and level of decision-making in intermediate and secondary schools was 3.08. This value is statistically significant. It also showed that the highest percentage of the study population considers that the obstacles to decision-making in general education schools in Medina are the high burden on the school principal and the lack of participation in decision-making.

Keung's (2015) [16] study, "The impact of participation in decision-making on improving the educational process," aimed to identify areas that would help school principals to involve teachers in decision-making. The researcher used the descriptive approach. The study was applied in Hong Kong on (20) secondary schools; the sample included (335) teachers, and the questionnaire was used as a data collection tool. The study concluded that teachers preferred to be involved in decisions regarding the educational model, curriculum, and management and that the involvement of teachers in decision-making has positive results affecting job satisfaction, commitment, and awareness of the workload.

Al-Rahmano's (2016) [10] study, "The relationship between participation in decision-making and some variables of the organizational climate in the scientific departments of the university: A case study of the branch of Taif University in Al-Khurmah," aimed to explore the phenomenon of participation in decision-making in university scientific departments, verify the relationship between participation opportunities, participation support methods, decision-making style, work pressure, and level of participation in decision-making in the university scientific department. The sample of the study consisted of male and female members of the teaching staff at the branch of Taif University in Al-Khurmah Governorate. The questionnaire was used to collect primary data. The study concluded that there is a fundamental relationship between the opportunities for participation in decision-making, the method of support by senior management to participate in decision-making, the decision-making style by the heads of departments, and the level of participation in decision-making in the scientific departments. It also concluded that there is no fundamental relationship between work stress and the level of participation in decision-making.

Dagher and Al-Kudah's study (2016) [14] "A reengineering model of the process of educational decision-making in Jordanian Universities," aimed at developing a reengineering model for the educational decision-making process in Jordanian universities. The sample consisted of (523) academic administrative officials in Jordanian universities. The results of the study indicate that assessment of the samples of the reality of the educational decision-making process in Jordanian Universities was high. The results also indicated that there 
is a statistically significant difference in the reality of educational decision-making process in Jordanian universities due to the nature of work in favor of the college Dean. The study concluded with the development of a reengineered model for the educational decision-making process in Jordanian universities and recommended its adoption.

The literature dealt, in general, with the issue of participation in the decision-making process in different areas. All studies used a descriptive approach and surveys. All studies used the questionnaire as a tool for gathering information, but it was noted that previous studies did not address the issue of participation in decision-making in the supervisory offices in Riyadh city.

\section{Methodological Study Procedures}

\subsection{Methodology}

The study was based on the descriptive approach. The study community's views on this subject were analyzed, and the information was classified. This method provides the opportunity to obtain accurate information and data about the study problem from the sample that represents the study population.

\subsection{The Study Sample and Population}

The study population consisted of subordinates at the supervisory offices in Riyadh city in the Kingdom of Saudi Arabia. According to the Sampson equation, the researcher selected a random sample of 198 of the total population of the study (408), to whom the questionnaires were distributed; the number of returned questionnaires was 150 .

\subsection{Data Collection Tool}

In collecting the data, the researcher relied on the questionnaire that included several themes according to the questions and objectives of the study. The questionnaire was subjected to the standards of honesty and consistency.

After the initial design of the questionnaire, it was presented to the jury of specialists who are experienced in research in educational administration. After consideration, the paragraphs of the questionnaire were redrafted according to the jury's views. After verifying the veracity of the study tool, the Pearson correlation coefficient was calculated to determine the validity of the questionnaire. The coefficient correlation between the degree of each statement of the questionnaire was calculated in the overall degree of the theme to which the statement belongs. The result was as follows:

Table 1. Pearson correlation coefficients between the score of each theme of the study to the overall score of each theme

\begin{tabular}{|c|c|c|c|c|c|}
\hline Statement No. & $\begin{array}{c}\text { Correlation } \\
\text { coefficient }\end{array}$ & Statement No. & Correlation coefficient & Statement No. & $\begin{array}{c}\text { Correlation } \\
\text { coefficient }\end{array}$ \\
\hline \multicolumn{6}{|c|}{ Levels of participation in decision-making } \\
\hline 1 & $0.449 * *$ & 4 & $0.702 * *$ & 7 & 0.798 \\
\hline 2 & $0.668 * *$ & 5 & $0.726^{* *}$ & - & - \\
\hline 3 & $0.722 * *$ & 6 & $0.746^{* *}$ & - & - \\
\hline \multicolumn{6}{|c|}{ Hindrances to participation in decision-making } \\
\hline 1 & $0.612 * *$ & 6 & $0.791 * *$ & 11 & $0.673 * *$ \\
\hline 2 & $0.668 * *$ & 7 & $0.777 * *$ & 12 & $0.735 * *$ \\
\hline 3 & $0.745 * *$ & 8 & $0.655^{* *}$ & 13 & \\
\hline 4 & $0.719 * *$ & 9 & $0.689 * *$ & - & - \\
\hline 5 & $0.704 * *$ & 10 & $0.686^{* *}$ & - & - \\
\hline \multicolumn{6}{|c|}{ Suggestions to develop participation in decision-making } \\
\hline 1 & $0.600 * *$ & 5 & $0.793 * *$ & 9 & $0.640 * *$ \\
\hline 2 & $0.636 * *$ & 6 & $0.781 * *$ & 10 & $0.481 * *$ \\
\hline 3 & $0.746 * *$ & 7 & $0.740 * *$ & - & - \\
\hline 4 & $0.825 * *$ & 8 & $0.774 * *$ & - & - \\
\hline
\end{tabular}

** Significant at the significance level of 0.01 and less.

It is clear from the above table that the correlation coefficient values of each statement with its theme is positive and statistically significant at the level of significance (0.01), indicating the validity of their consistency with the theme. To measure the stability of the study tool (the questionnaire), the researcher used Alpha Kronbach coefficient to confirm the stability of the study tool. The result was as follows:

Table 2. Alpha Cronbach coefficient consistency of the study themes

\begin{tabular}{|c|c|c|}
\hline Themes & No. of statements & Alpha Cronbach coefficient \\
\hline Levels of participation in decision-making & 7 & 0.847 \\
\hline Hindrances to participation in decision-making & 13 & 0.917 \\
\hline Suggestions to develop participation in decision-making & 10 & 0.878 \\
\hline
\end{tabular}


From Table (2), it is clear that the stability coefficient of the study themes is high, which indicates that the questionnaire has a high degree of stability that can be reliable in the field application of the study.

\subsection{Statistical Treatment Methods}

To achieve the objectives of the study and data analysis, many appropriate statistical methods were used applying the Statistical Package for Social Sciences (SPSS) after coding and inputting data to the computer.

The frequencies and percentages were calculated to identify the personal and functional characteristics of the study sample and to determine the responses of the participants to the main statements of the study tool.

The Pearson correlation coefficient was calculated between the score of each statement and the total score of the theme to which it belonged, in order to estimate the internal consistency of the study tool (structural honesty), and the Alpha Kronbach coefficient to measure the stability of the study tool. After that, the following statistical measures were calculated:

1) The arithmetic mean, to determine the extent of increase or decrease in the responses of the study population members on the main themes (statement averages)

2) Standard deviation, to identify the extent of deviation/dispersion of the answers of the study participants on each statement of the arithmetic mean of the answers, and for each of the main themes for their arithmetic mean.

\section{Study Results}

\subsection{Sample Characteristics}

Table 3. The arithmetic mean and the standard deviation for age and years of experience

\begin{tabular}{|c|c|c|c|c|}
\hline Variable & $\begin{array}{c}\text { Lowest } \\
\text { value }\end{array}$ & $\begin{array}{c}\text { Highest } \\
\text { value }\end{array}$ & $\begin{array}{c}\text { Arithmetic } \\
\text { mean }\end{array}$ & $\begin{array}{c}\text { Standard } \\
\text { deviation }\end{array}$ \\
\hline Age & 22 & 55 & 39.9 & 8.7 \\
\hline Experience & 1 & 35 & 17.1 & 7.9 \\
\hline
\end{tabular}

The data in Table 3 indicate that the arithmetic mean of age is 39.9. It can be said that the general arithmetic mean of the study sample's age is 40 years, with a standard deviation of 8.7; the lowest value was 22 years, and the highest value was 55 years.

It was shown that the arithmetic mean of experience was 17.1 , with the lowest value 1 , the highest value 35 , and the standard deviation 7.9.

Table 4. Distribution of the study samples by categories of academic qualification and job and nature

\begin{tabular}{|c|c|c|}
\hline Variable & Frequency & $\%$ \\
\hline \multicolumn{2}{|c|}{ Academic qualification } \\
\hline University degree & 117 & 78 \\
\hline Master & 11 & 7.3 \\
\hline PhD & 4 & 2.7 \\
\hline Other & 18 & 12 \\
\hline Supervisory & 74 & 49.3 \\
\hline Non-supervisory nature & 50.7 \\
\hline
\end{tabular}

Table 4 shows the distribution of the study sample according to the categories of qualification and job. The results in the table indicate that the majority of the respondents (78\%) are holders of bachelor's degrees, and $50.7 \%$ of those had non-supervisory jobs, while $49.3 \%$ had supervisory jobs.

\subsection{Answer to the Questions of the Study}

In this section, the researcher answers the questions of the study as follows:

\subsubsection{What Are the Levels of Participation in Decision-making by Subordinates in the Supervisory Offices in Riyadh City?}

To answer this question, the researcher calculated the frequency and relative distribution, arithmetical averages, and standard deviations of the responses of the study sample on the statements that measure the level of participation of subordinates in the decision-making process in the supervisory offices in Riyadh city. The following Table 5 illustrates this. 
Table 5. Answers of the study sample on the paragraphs of the theme of levels of participation in decision-making

\begin{tabular}{|c|c|c|c|c|c|c|c|c|c|c|}
\hline No. & \multicolumn{2}{|l|}{ Statements } & \begin{tabular}{|c|}
$\begin{array}{c}\text { Strongly } \\
\text { agree }\end{array}$ \\
\end{tabular} & Agree & Neutral & Disagree & \begin{tabular}{|l|l|} 
Strongly \\
disagree
\end{tabular} & $\begin{array}{l}\text { Arith. } \\
\text { Mean }\end{array}$ & $\begin{array}{l}\text { Standard } \\
\text { Deviation } \\
\end{array}$ & Order \\
\hline \multirow{2}{*}{1} & \multirow{2}{*}{$\begin{array}{l}\text { My manager makes the decision alone and then } \\
\text { informs subordinates to implement it }\end{array}$} & $\mathrm{K}$ & 57 & 56 & 13 & 18 & 5 & \multirow{2}{*}{3.95} & \multirow{2}{*}{1.1} & \multirow{2}{*}{1} \\
\hline & & $\%$ & 38 & 37.3 & 8.7 & 12 & 3.3 & & & \\
\hline \multirow{2}{*}{2} & \multirow{2}{*}{$\begin{array}{l}\text { My manager makes decisions and then tries to } \\
\text { convince subordinates with them }\end{array}$} & K & 40 & 59 & 21 & 21 & 7 & \multirow{2}{*}{3.7} & \multirow{2}{*}{1.2} & \multirow{2}{*}{6} \\
\hline & & $\%$ & 26.7 & 39.3 & 14 & 14 & 4.7 & & & \\
\hline \multirow{2}{*}{3} & \multirow{2}{*}{$\begin{array}{l}\text { My manager makes the decision then gives the } \\
\text { opportunity to subordinates to inquire about it to be } \\
\text { clear to them }\end{array}$} & $\mathrm{K}$ & 39 & 65 & 21 & 19 & 5 & \multirow{2}{*}{3.8} & \multirow{2}{*}{1.1} & \multirow{2}{*}{4} \\
\hline & & $\%$ & 26 & 43.3 & 14 & 12.7 & 3.3 & & & \\
\hline \multirow{2}{*}{4} & \multirow{2}{*}{$\begin{array}{l}\text { My manager listens to employees' opinions and } \\
\text { suggestions before making a final decision }\end{array}$} & K & 46 & 57 & 19 & 23 & 5 & \multirow{2}{*}{3.8} & \multirow{2}{*}{1.1} & \multirow{2}{*}{3} \\
\hline & & $\%$ & 30.7 & 38 & 12.7 & 15.3 & 3.3 & & & \\
\hline \multirow[b]{2}{*}{5} & \multirow{2}{*}{$\begin{array}{l}\text { My manager presents the problem to the subordinates } \\
\text { to contribute to finding alternatives and then he } \\
\text { chooses the alternative that he deems appropriate to } \\
\text { solve the problem }\end{array}$} & K & 45 & 65 & 10 & 27 & 3 & \multirow[b]{2}{*}{3.8} & \multirow[b]{2}{*}{1.1} & \multirow[b]{2}{*}{2} \\
\hline & & $\%$ & 30 & 43.3 & 6.7 & 18 & 2 & & & \\
\hline \multirow{2}{*}{6} & \multirow{2}{*}{$\begin{array}{l}\text { My manager involves subordinates as any other } \\
\text { member to reach the appropriate decision to make a } \\
\text { decision }\end{array}$} & $\mathrm{K}$ & 50 & 49 & 18 & 26 & 7 & \multirow{2}{*}{3.7} & \multirow{2}{*}{1.2} & \multirow[b]{2}{*}{5} \\
\hline & & $\%$ & 33.3 & 32.7 & 12 & 17.3 & 4.7 & & & \\
\hline \multirow{2}{*}{7} & \multirow{2}{*}{$\begin{array}{l}\text { My manager completely makes decisions through } \\
\text { subordinates }\end{array}$} & $\mathrm{K}$ & 31 & 45 & 20 & 31 & 23 & \multirow{2}{*}{3.2} & \multirow{2}{*}{1.4} & \multirow{2}{*}{7} \\
\hline & & $\%$ & 20.7 & 30 & 13.3 & 20.7 & 15.3 & & & \\
\hline
\end{tabular}

Table 5 shows the frequencies, percentages, arithmetic averages, and standard deviations of the responses of the study sample on the theme of decision-making levels. The data in the table indicate that the arithmetic average changes the tendency of the study sample to agree to apply the following levels in the decision-making process in the supervisory offices in the city of Riyadh:

1. "My manager makes the decision alone and then informs subordinates to implement it" has an arithmetic mean of 3.95 .

2. "My manager offers the problem to the subordinates to contribute to finding alternatives, and then he chooses the alternative that he deems appropriate to solve the problem" has an arithmetic mean of 3.8 .

3. "My manager listens to the views and suggestions of the staff before making a decision finally" has an arithmetic mean of 3.7.

The statement "My manager makes decision-making completely by subordinates" came in last, with an average of 3.2. This pattern of participation is related to authorizing the subordinates to diagnose the problem and to reach a decision. In this pattern, the decision-making is referred to the group. This pattern is extreme for the degree of freedom allowed for the group, as it leaves to them the task of identifying and diagnosing the problem, developing alternatives, and deciding the proper solution without forcing them to tell him the solution they reached.

It is clear from this that the levels of participation in decision-making among subordinates are various and varied and that they appear to be broad in terms of the extent of subordinates' freedom and their role in decision-making. This results in positive results reflected on the effectiveness and quality of the decision taken through participation, in addition to ensuring the success of this decision when it is carried out by the subordinates, as they are convinced of it and because it was issued by them and not imposed on them.

In the light of the above, the most important levels of participation in decision-making can be arranged as follows:

1. The manager makes the decision alone and then informs the subordinates for implementation.

2. The manager presents the problem to the subordinates to contribute to finding alternatives and then chooses the alternative that he deems appropriate to solve the problem.

3. The manager listens to the views of the subordinates and their suggestions before making a final decision.

\subsubsection{What Are the Obstacles That Prevent Participation in Decision-making in the Supervisory Offices in Riyadh City?}

In order to answer this question, the frequency, relative, and arithmetic distribution and the standard deviations of the responses of the study samples were calculated based on the statements that measure the level of participation of subordinates in the decision-making process in the supervisory offices in Riyadh City. The following table shows the same: 
The Reality of Participation in Decision-making: A Field Study on the Supervisory Offices in Riyadh City

Table 6. Answers of the study sample on the paragraphs of the theme of obstacles that prevent participation in decision-making

\begin{tabular}{|c|c|c|c|c|c|c|c|c|c|c|}
\hline No. & \multicolumn{2}{|l|}{ Statements } & \begin{tabular}{|c|}
$\begin{array}{c}\text { Strongly } \\
\text { agree }\end{array}$ \\
\end{tabular} & Agree & Neutral & Disagree & $\begin{array}{l}\text { Strongly } \\
\text { disagree }\end{array}$ & \begin{tabular}{|l|} 
Arith. \\
Mean \\
\end{tabular} & \begin{tabular}{|l|} 
Standard \\
Deviation \\
\end{tabular} & Order \\
\hline \multirow{2}{*}{1} & \multirow{2}{*}{$\begin{array}{l}\text { Limited delegation of decision-making power to } \\
\text { subordinates }\end{array}$} & $\mathrm{K}$ & 59 & 65 & 21 & 5 & - & \multirow{2}{*}{4.18} & \multirow{2}{*}{0.79} & \multirow{2}{*}{2} \\
\hline & & $\%$ & 39.3 & 43.3 & 14.0 & 3.3 & - & & & \\
\hline \multirow{2}{*}{2} & \multirow{2}{*}{$\begin{array}{l}\text { Lack of information necessary for the employee } \\
\text { to make the decision }\end{array}$} & $\mathrm{K}$ & 40 & 73 & 12 & 20 & 4 & \multirow{2}{*}{3.83} & \multirow{2}{*}{1.05} & \multirow{2}{*}{13} \\
\hline & & $\%$ & 26.7 & 48.7 & 8.0 & 13.3 & 2.7 & & & \\
\hline \multirow{2}{*}{3} & \multirow{2}{*}{ Decision-making procedures are complex } & $\mathrm{K}$ & 52 & 57 & 20 & 15 & 4 & \multirow{2}{*}{3.93} & \multirow{2}{*}{1.06} & \multirow{2}{*}{6} \\
\hline & & $\%$ & 34.7 & 38.0 & 13.3 & 10.0 & 2.7 & & & \\
\hline \multirow{2}{*}{4} & \multirow{2}{*}{$\begin{array}{c}\text { Inaccuracy of information available to the } \\
\text { employee }\end{array}$} & $\mathrm{K}$ & 50 & 65 & 13 & 18 & 4 & \multirow{2}{*}{3.92} & \multirow{2}{*}{1.06} & \multirow{2}{*}{7} \\
\hline & & $\%$ & 33.3 & 43.3 & 8.7 & 12.0 & 2.7 & & & \\
\hline \multirow{2}{*}{5} & \multirow{2}{*}{ Not delegating authority to subordinates } & $\mathrm{K}$ & 58 & 60 & 17 & 15 & - & \multirow{2}{*}{4.07} & \multirow{2}{*}{0.94} & \multirow{2}{*}{3} \\
\hline & & $\%$ & 38.7 & 40.0 & 11.3 & 10.0 & - & & & \\
\hline \multirow{2}{*}{6} & \multirow{2}{*}{$\begin{array}{c}\begin{array}{c}\text { Weakness of the managers' knowledge of the } \\
\text { appropriate methods of participation in the work } \\
\text { tasks }\end{array} \\
\end{array}$} & $\mathrm{K}$ & 45 & 62 & 21 & 14 & 7 & \multirow{2}{*}{3.83} & \multirow{2}{*}{1.10} & \\
\hline & & $\%$ & 30.0 & 41.3 & 14.0 & 9.3 & 4.7 & & & 10 \\
\hline 7 & 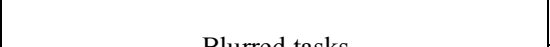 & $\mathrm{K}$ & 47 & 65 & 14 & 18 & 6 & 386 & 111 & 8 \\
\hline 1 & Divicut tasks & $\%$ & 31.3 & 43.3 & 9.3 & 12.0 & 4.0 & 0.00 & 1.11 & 0 \\
\hline$e$ & 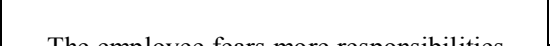 & K & 46 & 57 & 18 & 20 & 8 & 275 & 118 & 12 \\
\hline 8 & The employee fears more responsibilities & $\%$ & 30.7 & 38.0 & 12.0 & 13.3 & 5.3 & 3.15 & 1.18 & 12 \\
\hline 0 & Or & $\mathrm{K}$ & 49 & 52 & 21 & 22 & 5 & 270 & 1,15 & 11 \\
\hline (3) & Uverwork lor subordmates & $\%$ & 32.7 & 34.7 & 14.0 & 14.7 & 3.3 & 3.19 & 1.15 & 11 \\
\hline 10 & Poor aunlificotion of omplowec & $\mathrm{K}$ & 47 & 60 & 20 & 19 & 4 & 384 & 100 & 0 \\
\hline 10 & Poor quantication or empioyees & $\%$ & 31.3 & 40.0 & 13.3 & 12.7 & 2.7 & 3.84 & 1.08 & 9 \\
\hline 11 & 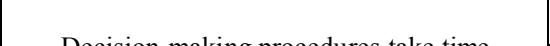 & K & 55 & 67 & 12 & 9 & 6 & 104 & 100 & 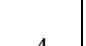 \\
\hline 11 & Dectsion-making piocedures take tinte & $\%$ & 36.7 & 44.7 & 8.0 & 6.0 & 4.0 & 4.04 & 1.02 & 4 \\
\hline 12 & Poluctance in focing nroblems & $\mathrm{K}$ & 53 & 61 & 21 & 12 & 3 & 300 & 0.00 & 5 \\
\hline 12 & 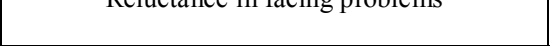 & $\%$ & 35.3 & 40.7 & 14.0 & 8.0 & 2.0 & ( & 0.79 & J \\
\hline 13 & Lack of efficient leadership limits staff & $\mathrm{K}$ & 71 & 57 & 15 & 3 & 4 & 425 & 0.91 & 1 \\
\hline 13 & participation in decision-making & $\%$ & 47.3 & 38.0 & 10.0 & 2.0 & 2.7 & 4.25 & 0.91 & 1 \\
\hline & Gener & 1 ave & rage & & & & & 3.9 & 1.0 & \\
\hline
\end{tabular}

Table (6) shows the frequencies, percentages, arithmetic mean and the standard deviations of the responses of the study participants on the paragraphs of the theme of obstacles that prevent participation in decision-making. The data in the table indicate that the general mean of the theme reached (3.9). This is an indicator of the tendency of the responses of the study participants to agree on the statements in the theme, and the standard deviation reached (1.0). This is an indication of the dispersion of the study participants relative to the statements of the theme. The problems came in the following order:

1. Lack of efficient leadership limits staff participation in decision-making, with an average of (4.25).

2. Limited delegation of decision-making authority to subordinates, with an average of (4.18).

3. Failure to delegate the powers to subordinates, with an average of (4.07), and in the last order came lack of information needed for the employee to make a decision, with an average of (3.8).

In light of the above, the key obstacles to participation in decision-making can be arranged as follows:

1. Lack of efficient leadership limits the employees' participation in decision-making.

2. Limited delegation of decision-making power to subordinates.

3. Non-delegation of powers to subordinates.

\subsubsection{What Are the Suggestions for Developing}

Participation in the Decision-making of the

Supervisory Offices in Riyadh City?

To answer this question, the frequency, relative, and arithmetic mean and the standard deviations of the participants' responses were calculated based on the statements that measure the level of participation of staff in the decision-making process at the supervisory offices in Riyadh City. Table (7) illustrates this. 
Table 7. Answers of the study sample on the paragraphs of the theme of proposals for the development of participation in decision-making

\begin{tabular}{|c|c|c|c|c|c|c|c|c|c|c|}
\hline No. & \multicolumn{2}{|l|}{ Statements } & $\begin{array}{c}\begin{array}{c}\text { Strongly } \\
\text { agree }\end{array} \\
\end{array}$ & Agree & Neutral & Disagree & $\begin{array}{l}\text { Strongly } \\
\text { disagree }\end{array}$ & $\begin{array}{l}\text { Arith. } \\
\text { Mean }\end{array}$ & $\begin{array}{l}\text { Standard } \\
\text { Deviation }\end{array}$ & Order \\
\hline \multirow[b]{2}{*}{1} & \multirow{2}{*}{$\begin{array}{l}\text { Accommodate the working environment before } \\
\text { making the decision to reduce resistance to the } \\
\text { implementation of the decision }\end{array}$} & $\mathrm{K}$ & 77 & 53 & 15 & 3 & 2 & \multirow{2}{*}{4.33} & \multirow{2}{*}{0.84} & \multirow{2}{*}{8} \\
\hline & & $\%$ & 51.3 & 35.3 & 10.0 & 2.0 & 1.3 & & & \\
\hline \multirow{2}{*}{2} & \multirow{2}{*}{ Delegation of powers to subordinates } & $\mathrm{K}$ & 61 & 76 & 10 & 3 & - & \multirow{2}{*}{4.30} & \multirow{2}{*}{0.68} & \multirow{2}{*}{9} \\
\hline & & $\%$ & 40.7 & 50.7 & 6.7 & 2.0 & - & & & \\
\hline \multirow{2}{*}{3} & \multirow{2}{*}{ Holding periodic meetings with subordinates } & $\mathrm{K}$ & 69 & 70 & 7 & 4 & - & \multirow{2}{*}{4.36} & \multirow{2}{*}{0.69} & \multirow{2}{*}{7} \\
\hline & & $\%$ & 46.0 & 46.7 & 4.7 & 2.7 & - & & & \\
\hline \multirow{2}{*}{4} & \multirow{2}{*}{ Encourage subordinates to make proposals at work } & $\mathrm{K}$ & 76 & 63 & 7 & 3 & 1 & \multirow{2}{*}{4.40} & \multirow{2}{*}{0.73} & \multirow{2}{*}{5} \\
\hline & & $\%$ & 50.7 & 42.0 & 4.7 & 2.0 & 0.7 & & & \\
\hline \multirow{2}{*}{5} & \multirow{2}{*}{ Managers appreciate the thoughts of subordinates } & $\mathrm{K}$ & 77 & 59 & 4 & 7 & 1 & \multirow{2}{*}{4.37} & \multirow{2}{*}{0.81} & \multirow{2}{*}{6} \\
\hline & & $\%$ & 51.3 & 39.3 & 2.7 & 4.7 & 0.7 & & & \\
\hline \multirow{2}{*}{6} & \multirow{2}{*}{ Provide information necessary for decision making } & $\mathrm{K}$ & 79 & 61 & 6 & 3 & 1 & \multirow{2}{*}{4.42} & \multirow{2}{*}{0.72} & \multirow{2}{*}{4} \\
\hline & & $\%$ & 52.7 & 40.7 & 4.0 & 2.0 & 0.7 & & & \\
\hline \multirow{2}{*}{7} & \multirow{2}{*}{$\begin{array}{l}\text { Subordinates should have a good knowledge of the } \\
\text { methods of participation suitable for the work tasks }\end{array}$} & $\mathrm{K}$ & 84 & 58 & 5 & - & 3 & & & \\
\hline & & $\%$ & 56.0 & 38.7 & 3.3 & - & 2.0 & 4.46 & 0.74 & 2 \\
\hline 8 & Hold training sessions for managers on delegation & $\mathrm{K}$ & 83 & 56 & 9 & - & 2 & & & \\
\hline 8 & of authority & $\%$ & 55.3 & 37.3 & 6.0 & - & 1.3 & 4.45 & 0.72 & 3 \\
\hline & Hold training courses for subordinates so that their & $\mathrm{K}$ & 86 & 56 & 5 & 2 & 1 & & & \\
\hline 9 & participation in the decision-making is fruitful & $\%$ & 57.3 & 37.3 & 3.3 & 1.3 & 0.7 & 4.49 & 0.69 & 1 \\
\hline & & $\mathrm{K}$ & 54 & 57 & 14 & 17 & 6 & & & \\
\hline 10 & Reduce the scope of administrative supervision & $\%$ & 36.0 & 38.0 & 9.3 & 11.3 & 4.0 & 3.91 & 1.13 & 10 \\
\hline & General a & vera & & & & & & 4.4 & 0.78 & \\
\hline
\end{tabular}

Table (7) shows the frequencies, percentages, arithmetic means and the standard deviations of the responses of the study participants on the paragraphs on the focus of the respondents' proposals for the development of participation in decision making. The data in the table indicate that the general arithmetic mean of the theme was 4.4 , which is an indication of the tendency of the participants' responses to agree with the statements in the theme. The standard deviation was 0.78 , which indicates the consistency of the study samples regarding answering the statements of the theme.

First came the statement: Give interest to holding training courses for subordinates so that their participation in the decision-making is fruitful, with an average of 4.49. Second came the statement: Subordinates should have a good knowledge of the methods of participation suitable for the tasks of work, with an average of 4.46. Third came the statement: Hold training courses for managers on the delegation of authority, with an average of 4.45 . Last came the statement: Reduce the scope of administrative supervision, with an average of 3.91 .

In light of the above, the key suggestions of the respondents to develop participation in the decision-making process can be arranged as follows:

1. Give interest in training courses for subordinates so that their participation in decision-making is fruitful.
2. Subordinates should have a good knowledge of the methods of participation that are appropriate for the work tasks.

3. To hold training sessions for managers on delegation of authority.

In light of the above, the key suggestions of the respondents to develop participation in the decision-making process can be arranged as follows:

\section{Summarized Findings and Recommendations}

\subsection{Summary of Findings}

The study reached several findings as follows:

5.1.1. The order of the key levels of participation in decision-making was as follows:

A. The manager makes the decision alone, and then informs the subordinates to implement it.

This mode of participation is related to the senior's decision-making, and then informing his subordinates: In this mode, the manager makes the decision alone, and then informs his subordinates to implement it. In this case, the 
manager determines the objective or the problem and identifies the alternatives, chooses the right alternative, and then informs his subordinates to implement it. The manager may or may not give weight about what his subordinates think about his decision. In any event, he does not allow them any opportunity to participate directly in the decision-making process, and may resort to forcing his subordinates to accept the decision he made, taking advantage of his official means of authority, or at least refer to using it.

B. The manager presents the problem to subordinates to contribute to finding alternatives, and then chooses the alternative that he deems appropriate to solve the problem.

This mode of participation is related to the manager's presentation of the problem and his call to the subordinates to submit proposals and solutions. In this mode, the manager presents the problem to the group and asks them to submit their proposals regarding all possible alternatives to solve the problem. After the extensive discussion of each of these alternatives, he chooses the proper one. In this mode, we find that the group has contributed effectively to the development of possible alternatives to solve the problem and has played an influential role in the decision-making.

C. The manager listens to the views and suggestions of the staff before making his decision.

This mode of participation is related to the manager's making a preliminary decision, leaving the room open for change. The manager makes a preliminary decision that is capable of amendment, and then calls his subordinates for discussion. After listening to the opinions and proposals, he makes the decision himself. In this mode, the decision to identify and diagnose the problem remains in the hands of the manager; he does not try to make a final decision, but rather, form a preliminary decision to present it to the subordinates to know their point of view and listen to their proposals. However, the final decision remains with him.

In this regard, Al-Sufiani's (2012) [11] study found that the degree of participation of teachers in making school-related decisions in general was low, with an average of 3.44 .

The study of Mohammed (2013) [18] found that the level of participation in decision-making among faculty members in Algerian universities was generally low. In Castler's (2014) [13] study, it was found that the participation of teachers in decentralized management schools was better than that of teachers in centralized schools. Decentralized schools tended to have a more open climate than schools with centralized management.

In Al-Ghamdi's (2015) [4] study, it was found that the general average of the views of the study community on the reality and level of decision-making in intermediate and high schools was 3.08 , which is statistically significant. In
Keung's (2015) [16] study, it was found that teachers preferred to get involved in decisions in the educational model, curriculum, and management fields and that the involvement of teachers in decision-making had positive results affecting job satisfaction, commitment, and awareness of the workload.

\subsubsection{The key obstacles to participation in} decision-making came in the following order:
A. Lack of efficient leadership
B. Limited delegation of decision-making power to subordinates
C. Not delegating powers to subordinates.

In this regard, Al-Ghamdi's (2015) [4] study found that the obstacles managers face in decision-making in general education schools in Medinah are the high burdens placed on the principal, reaching (22.05), and the lack of participation in decision-making, reaching (17.6\%).

Larry's (2013) [17] study found that teachers need experience and training to increase their desired effectiveness in decision-making.

\subsubsection{The key suggestions of the respondents to develop participation in decision-making were as follows:}
A. Show interest in holding training courses for subordinates so that their participation in decision-making is fruitful.
B. The subordinates should have good knowledge of the methods of participation suitable for the tasks of work.
C. Hold training courses for managers on the delegation of authority.

In this regard, Larry's (2013) [17] study found that teachers need experience and training to increase their desired decision-making effectiveness, and teachers in intermediate schools recognized the need to involve students in decision-making.

\subsection{Recommendations}

In light of the findings reached, a set of recommendations and proposals could be developed that could contribute to the development of participation in decision-making as follows:

1. Hold training courses for subordinates so that their participation in decision-making is fruitful.

2. Encourage leaders to delegate authority and powers to subordinates in order to avoid the problems of centralization, as the delegation of powers helps in running the affairs and tasks of work without delay because the leader whose duty continuously requires him and whose duty is paralyzed by his absence is considered an unsuccessful leader, as he did not develop his assistants and did not give them the necessary 
powers. Therefore, training sessions should be held for managers on the delegation of authority.

3. The subordinates should have a good knowledge of the methods of participation suitable for the work tasks.

4. Provide the necessary information for decision-making and take into account the accuracy of this information.

5. Encourage subordinates to provide proposals at work and encourage them to take responsibility and improve performance methods.

6. Accommodate the external and internal environment of the organization before making the decision in order to reduce resistance to the implementation of the decision.

\section{Acknowledgements}

The author would like to thank all those who facilitated the research.

\section{REFERENCES}

[1] Abdul Rasoul, Mahmoud Abou El Nour (2010). The Relationship of Participation in Decision Making to Leadership Patterns of Principals of Primary Schools in Egypt, a Field Study. Cairo, Journal of the Faculty of Education, Volume (13), issue (27), pp. 103-156.

[2] Abu Allam, Rajaa Mahmoud. (2014). Decision making and its relation to the emotional intelligence of educational leaders in the light of some demographic variables. Cairo, Journal of Educational Sciences, vol. 22, third issue, pp. 533-566.

[3] Al-Amri, Suhaila (2011). Impact of participation of UNRWA staff in decision-making on their job performance. Unpublished Master dissertation, Gaza, Islamic University.

[4] Al-Ghamdi, Ali bin Mohammed (2015). The reality of the decision-making process of the principals of public education schools in Madinah. University of Taibah, Journal of the Arabian Gulf Message, vol. 369, issue 137, pp. 69-88.

[5] Al-Harahsha, Mohamed Abboud (2014). The degree of practicing decision-making patterns among the managers of the schools of the Education Dept. in Qasabat Al-Mafraq Governorate in Jordan. Kuwait, Educational Journal, vol. 289 , issue. 112, pp. 181-226.

[6] Al-Hassoun, Aisha Husni Hamed (2017) A proposed model for increasing the participation of government high school teachers in the school decision-making process in the capital of Jordan, Studies Journal, Educational Sciences, Jordan, Vol. 44, Issue 2, pp. 346-319.

[7] Al-Hourani, Nawal Abdul Rahman. (2013). A comparison of how decision is made among male and female managers, a case study on UNRWA's education program. Gaza,
Islamic University.

[8] Al-Khamis, Abdulaziz bin Mohammed. (2011) Participation in administrative decision-making and its role in reducing resistance to organizational change from the point of view of the officers working the National Guard Headquarters. Unpublished Master Dissertation, Naif Arab University for Security Sciences, College of Graduate Studies, Department of Administrative Sciences.

[9] Al-Qahtani, Ali Fahran Mohammed (2016). Features of educational decision-making in the Ministry of Education in Saudi Arabia. Cairo, Journal of Reading and Knowledge, Volume 4, issue 181, pp. 141-163.

[10] Al-Rahmano, Mohammed Abu Bakr (2016). The relationship between participation in decision-making and some variables of the organizational climate in the academic departments: A case study on the branch of Taif University in Al-Khurmah. Journal of the American Arab Academy for Science and Technology. Volume 7, issue 20, pp. 25-44.

[11] Al-Sufiani, Majid bin Safar (2012). The degree of teachers' participation in the school decision making, a field study from the point of view of secondary school teachers in Taif. Unpublished Master Dissertation, Umm Al Qura University, Faculty of Education, Department of Educational Administration and Planning.

[12] Al-Swaidi, Thaer Mohammed, (2014). Decision-making and its relationship to the leadership behavior of school principals in Wasit Governorate from the point of view of assistants and teachers. Baghdad, Journal of Educational and Psychological Sciences, issue 104, pp. 1-6.

[13] Castler, Gaylord (2014). Judgment Analysis of school superintendent decision in Minnesota State. Minnesota State University: Journal of Experimental Evaluation, Vol. 57 , No. 1 , pp. $87-96$

[14] Dagher, Azhar Kheder, and Al-kudah, Mohamed Amin. (2016). A model for the reengineering of decision-making process in Jordanian universities. Amman, Journal of Educational Sciences, vol. (43), First Issue, pp. 781-802.

[15] Dalton, Fredrick (2014), Middle School Teacher Involvement In Site Based Decision Making, University of Texas At Austin Proudest, Dissertation Abstract.

[16] Keung, Cheng (2015). The Effect of Shared Decision-Making on the Improvement in teachers' Job Development. Educational Administration Quarterly, No.14, pp $(27-41)$.

[17] Larry, Latinor (2013), "Perception of Teachers at Select Middle School on the Role of Teachers in Shared Decision Making in Waybe State Region. Waybe State University. Dissertation Abstracts International, Vol. (54), No. (3). p 678.

[18] Mohammed, Rib Allah (2013), the reality of participation in decision-making among faculty members in Algerian universities, a field study, the Arab Journal for Quality Assurance of University Education, issue (11). pp. 44-62.

[19] Mustafawi, Mustafa (2017), the contribution of decision-making in the sense of job satisfaction, Al-Hikma Journal of Social Studies, Kunooz Al-Hikma Foundation for Publishing and Distribution, Algeria, Issue (11) pp. 
98-82.

[20] Rizk, Rashed Marzouk, (2013). Components of emotional intelligence and its relationship to the decision-making skills of school principals. Cairo, Educational Magazine, Issue 34, pp. 223-227.

[21] Shalaby, Karima Shalaby (2015). The problem of weak participation of workers in decision-making in governmental organizations. Cairo, Journal of Management, Volume (52), Issue (3), pp. 13-23.
[22] Shehab, Ibrahim, (1995). Staff participants in administrative decision making. Muscat, Administrative Journal, issue (61), pp. 205-226.

[23] Sobh, Mohamed Hassan (2015). Methods of thinking and their relation to the decision-making ability of primary school teachers. Egypt, Journal of the Faculty of Education, Volume 1, issue (18), pp. 844-871.

[24] Zeitouni, Samia, (2015). Obstacles affecting sound decision making process. Algeria, Journal of Law and Human Sciences, Volume 2, issue 21, pp. 168-178. 